\title{
Interdisciplinaridade, Serviço Social e penas alternativas: entre a tutela institucional e a emancipação dos sujeitos em conflito com a lei.
}

\author{
The Interdisciplinary, Social Service and alternative penalties: between the tutelage and \\ the independence of people in conflict with the law.
}

Marcos Francisco de Souza*

\begin{abstract}
Resumo:
O presente artigo tem como objetivo introduzir uma discussão sobre a interdisciplinaridade como alternativa metodológica de superação do modelo tradicional de ciência que prima pela fragmentação dos vários aspectos da vida social. Além disso, procura analisar no âmbito judiciário da aplicação de penas e medidas alternativas o paradoxo entre a tutela institucional e a emancipação dos sujeitos judicializados, bem como as possibilidades teóricas, técnicas e institucionais de se pensar em práticas interdisciplinaridades no contexto do assessoramento psicossocial prestado por assistentes sociais, psicólogos e pedagogos do Tribunal de Justiça do Distrito Federal e Territórios.
\end{abstract}

Palavras-chaves: Interdisciplinaridade; Penas alternativas; Responsabilização; Serviço Social.

\begin{abstract}
:
This presents paper has the objective to discuss about the interdisciplinary methodology alternative to overcoming the traditional model science that divides or give autonomy the different aspects of social life. Also, it analyzes the paradox between the tutelage and the independence of people in conflict with the law in the circumstance of application of the alternative sentences and measures, and as well as the theoretical possibilities, technical and institutional to think about interdisciplinary practices in the context of psychosocial assistance it has been done by social workers, psychologists and educators of the Justice Court of Federal District.
\end{abstract}

Key-words: Interdisciplinary; Alternative penalties; Responsibility; Social Service.

\section{Introdução}

O termo interdisciplinaridade tem sido cada vez difundido nos discursos e nas práticas institucionais na intenção de brotar mudanças qualitativas nas formas de

\footnotetext{
"Mestre em Política Social, atuando no Tribunal de Justiça do Distrito Federal e Territórios - TJDFT E-mail: marcosfsoueu@yahoo.com.br ou marcos.souza@tjdft.jus.br
} 
compreender e explicar as complexas, múltiplas e heterogêneas demandas dos usuários atendidos.

Da mesma forma, ela tem se tornado uma alternativa metodológica de explicação da realidade por parte de algumas correntes teóricas nas ciências humanas e sociais que fazem crítica ao modelo tradicional de ciência, que foi responsável pela fragmentação do ser e do saber produzido sobre a realidade.

Esta fragmentação foi responsável pelos excessos de especializações que invadiram o universo científico e profissional, e tornaram cada vez mais reduzidas e superficiais as teorias explicativas da realidade humana e social.

Hoje, parece haver o início de um processo reversivo que impõe uma tomada de posição na direção da "desreificação" da linearidade do conhecimento teórico-prático tradicional. Assim, a dinamicidade, complexidade e heterogeneidade da realidade social denunciam a dificuldade deste modelo tradicional manter-se epistemologicamente hegemônico na forma de construir as suas supostas e equivocadas verdade absoluta.

Ilustrativamente, a utilização de profissionais da Psicologia, do Serviço Social, da Pedagogia e áreas afins no judiciário brasileiro para assessorar as decisões judiciais ${ }^{1}$ denuncia, de certa forma, a incapacidade do saber linear e unívoco da ciência do Direito de dar respostas concretas e efetivas aos conflitos vividos pelos sujeitos judicializados ${ }^{2}$. Por outro lado, representa o passo inicial de um percurso reflexivo que precisa ser estimulado, primeiramente, entre os profissionais que compõem este assessoramento e, no segundo momento, entre estes profissionais e os operadores da lei (juízes, promotores, advogados e defensores públicos).

Com isso, levantamos como hipótese norteadora do presente artigo a possibilidade de pensarmos em práticas interdisciplinares no contexto do judiciário e, caso positivo, pensarmos sobre os paradoxos que norteiam o trabalho dos profissionais que atuam na

\footnotetext{
${ }^{1}$ Apesar de não haver, em nível nacional, uma pesquisa que analise o nível e a abrangência da utilização de profissionais do Serviço Social e da Psicologia e áreas afins no assessoramento aos magistrados, parece que existe uma tendência crescente, cada vez mais crescente, da incorporação destes profissionais participando diretamente na resolução dos conflitos criminais, cíveis e infracionais. Ver Souza (2004).

2 Entendemos por sujeito judicializado todo cidadão que está sob a tutela do judiciário em virtude da materialização ou expressão de um conflito ou dissenso com outro cidadão, grupo ou segmentos sociais específicos ou ainda com o próprio Estado.
} 
equipe "psicossocial"³ da Vara de Execução das Penas e Medidas Alternativas (VEPEMA). Para isso, faremos, no primeiro momento, um retrospecto histórico e conceitual da construção do pensamento moderno no que diz respeito, principalmente, à consolidação do Saber Científico como representante e produtor legítimo da Verdade (MINAYO,1994).

No segundo momento, apontaremos como a divisão social do trabalho na ciência (e o seu excesso) acabou dividindo e simplificando a realidade humana e social, trazendo armadilhas teórico-metodológicas e prático-reflexivas aos profissionais que dela se utilizam para construir Verdades Absolutas sobre os seus usuários ${ }^{4}$, suas famílias e suas redes sociais.

Por último, de forma reativa, pretendemos problematizar o lugar do Serviço Social nas equipes multiprofissionais denominadas de "psicossociais" e a interdisciplinaridade como o "caminho do meio" que deve estar presente no posto paradigma da tutela, da responsabilização, do "cuidado" profissional e da emancipação dos sujeitos judicializados no âmbito das penas e medidas alternativas.

\section{O paradigma Positivista de Ciência e a Produção de Verdades e Saberes}

Para começar, podemos dizer que há uma inquietação que sempre mobilizou o homem: a etiologia da sociabilidade humana. E não faltaram conflitos de posições entre os estudiosos da filosofia, da teologia e da ciência (no sentido tradicional) que, na azáfama de explicarem e compreenderem a realidade humana e social, problematizaram e polemizaram as complexas e contraditórias relações entre sujeito e estrutura, entre o

\footnotetext{
${ }^{3}$ As aspas são utilizadas para destacar que o termo é hegemonicamente utilizado no Tribunal de Justiça do Distrito Federal e Territórios, o qual, regimentalmente, qualifica os setores que prestam assessoria aos magistrados das áreas cíveis, criminais e infracionais, nas áreas de Serviço Social, Psicologia e Pedagogia. Ver Souza (2004).

4 Ao longo do texto o termo "usuário" será identificado, também, como "sujeito em conflito com a lei" e "sujeito judicializado" para caracteriza-lo pela forma particular de nomear e qualificar os indivíduos tutelados pela Vara de Execução das Penas e Medidas Alternativas do Tribunal de Justiça do Distrito Federal e Territórios. A VEPEMA possui como atribuição básica realizar a execução, fiscalização e acompanhamento das penas e medidas alternativas na circunscrição judiciária do Distrito Federal.

${ }^{5}$ A utilização do termo "cuidado" profissional se deve ao fato de ser um termo amplamente utilizado no discurso dos profissionais que prestam assessoria psicossocial. Da mesma forma, o termo é utilizado, aqui, no sentido da emancipação dos usuários na perspectiva da escuta e do acolhimento profissional, com vistas à garantia das condições sócio-institucionais, técnico-profissionais e ético-políticas de acesso aos seus direitos de cidadania.
} 
individual e o coletivo, entre particular e o universal, entre o simples e o complexo e, no que diz respeito ao objeto do presente artigo, a relação entre o "psíquico" e o "social”6.

Cervo e Bervian (1983) fazem uma distinção, que entendemos mais didática que metodológica, entre os quatro tipos de conhecimento que o homem produz sobre a realidade, ou seja, sobre a busca da Verdade: o empírico ${ }^{7}$, o filosófico, teológico e o científico. São tipos de conhecimento que, do nosso ponto de vista, estão presentes em todos os tipos de sociedade, de forma mais ou menos predominante e com conteúdos políticos e ideológicos variáveis historicamente.

Pelo conhecimento filosófico, a expressão da condição humana esta na existência pura e simples de uma consciência nata que atribui, ao homem, uma racionalidade única e exclusiva do humano, distinta da natureza animal, de modo que a percepção que tinha do mundo exterior provém da observação pura e simples dos fenômenos naturais e sociais.

Apenas com o surgimento da economia política feudal entre os séculos V e XII é que as bases explicativas da realidade humana e social serão sustentadas pelo conhecimento religioso cristão que revela ao homem a Verdade sobre si mesmo, sobre a natureza e sobre as coisas do mundo (economia, política, cultura, linguagem, religião, pobreza, riqueza...).

Do ponto vista da explicação e compreensão do processo de sociabilidade humana, tanto o conhecimento empírico quanto o filosófico e o religioso, apesar de criarem paradigmas explicativos do real, esgotaram os seus pressupostos pelas suas próprias dinâmicas internas, como denunciara o conhecimento científico que marcou o surgimento do pensamento econômico-político moderno nos séculos XIV/XV, sobremaneira, nos países europeus (CARNOY, 2000).

O advento da idéia de modernidade introduziu um novo paradigma baseado numa racionalidade científica que provocou um processo de cientificização do cotidiano e de profissionalização de determinadas práticas sociais, donde se destaca a psicologia, o direito, a economia, a antropologia, a sociologia e o serviço social.

\footnotetext{
${ }^{6}$ Ver Etgs (1995), Frigotto (1995), Muchail (1995), Sawaia (1995).

${ }^{7}$ O conhecimento empírico, segundo o autor, está baseado na experiência imediata, no aparente. É, segundo o autor, o lugar do senso-comum, ou seja, do imediato, acrítico e ilusório porque emite uma visão equivocada e simplista da realidade. O terreno metodológico de explicação da realidade está assentado, muitas vezes, nos valores morais e nos juízos de valor da pessoa.
} 
Entretanto, se de um lado o conhecimento científico representou uma quebra do paradigma religioso-cristão que atribuía às leis divinas a explicação e compreensão da realidade, por outro, trouxe o equívoco de explicar os fenômenos humano-sociais utilizando os mesmos métodos de explicação dos fenômenos naturais, a partir do entendimento de que o homem, apesar de autônomo, era parte constituinte da própria natureza (CERVO; BERVIAN, 1983; THOMPSON, 1983).

A base explicativa desse pressuposto científico está na idéia de que não estando mais subordinado a uma verdade divina, o homem era um ser dotado de uma razão própria que é característica da "natureza humana" e, sendo parte da natureza, todos os fenômenos produzidos socialmente eram vistos como um produto natural da lógica social (SOUZA, 2004).

Isto quer dizer que, como na natureza os fenômenos estão lá, postos, dados, restando ao homem apenas utilizar os métodos adequados para descobri-los, na sociedade também ${ }^{8}$. E, com isso, inaugura-se o paradigma científico conhecido como positivismo que tanto influenciou as ciências humanas e sociais, bem como foi base de teorias explicativas da realidade como o funcionalismo, o estruturalismo e o sistemismo ${ }^{9}$.

O método científico se consolidou apoiado na busca de um conhecimento objetivo sobre a realidade humana e social, partindo do pressuposto de uma suposta "neutralidade" do sujeito (pesquisador) em relação ao seu objeto de conhecimento (pesquisado). De igual modo, apoiou-se na observação e na experimentação para, assim, se chegar a leis universais e invariáveis, seguindo o mesmo percurso metodológico das ciências naturais (CERVO; BERVIAN, 1983; TRIVIÑOS, 1992).

Logo, o método científico tradicional, ao revelar a evidência e a certeza da Verdade Absoluta sobre os diferentes objetos de estudo da natureza humana e social, passou a orientar todo o processo de divisão do trabalho na "comunidade científica", de forma que

\footnotetext{
${ }^{8}$ A título de exemplo desta apropriação do método das ciências naturais para explicar os fenômenos sociais podemos destacar: a lei de causa e efeito (a pobreza causa a marginalidade); a lógica matemática do todo como soma das partes, apropriada pela teoria do funcionamento social; a idéia do darwinismo social baseada na teoria da evolução das espécies.

${ }^{9}$ Ribeiro (2001).
} 
todo campo de conhecimento que se propunha científico só poderia adquirir, epistemologicamente, legitimidade e reconhecimento pela utilização deste método ${ }^{10}$.

Esta prerrogativa fez com que muitas áreas de conhecimento privilegiadamente reflexivas e interventivas (como o Direito, a Psicologia e o Serviço Social) perseguissem o status de Ciência incorporando, de forma acrítica, o método das ciências naturais.

Como conseqüência, a simplificação da realidade trouxe implicações teóricoanalíticas e prático-reflexivas para as ciências humanas e sociais, que eclodiram num movimento de crítica ao reducionismo metodológico positivista e a necessidade de se trilhar um caminho metodológico próprio que considerasse o caráter histórico, dinâmico, complexo e heterogêneo da realidade humano-social (MINAYO, 1994; GOLDENBERG, 1997; HAGUETE, 2000).

Primeiro, porque o homem é um ser político e histórico e não pode ser apreendido como um objeto exato, inerte e homogêneo. Como diz Thompson (1983, p.42) "o homem é, a um só tempo, sujeito e objeto dele mesmo", de forma que não se pode falar em neutralidade, pois a subjetividade do sujeito-pesquisador está presente durante todo o processo de conhecimento e intervenção do/sobre objeto.

Segundo, sendo um ser político e histórico, o homem constrói a sua própria realidade dando múltiplos, heterogêneos e contraditórios significados e sentidos aos seus pensamentos e suas ações.

Assim, avessa à visão unívoca e linear positivista de uma realidade existente independente da vontade do sujeito, a crítica funda-se na direção de uma realidade construída social e historicamente que reposiciona o papel do próprio homem (enquanto sujeito) no seu processo de sociabilidade.

Igualmente, desmascara o pilar político-ideológico do processo de naturalização e individualização de fenômenos que, ao contrário, possuem determinantes sóciohistóricos, e que se tornam objeto de estudo e análise dos assistentes sociais e psicólogos que assessoram os magistrados da justiça do Distrito Federal.

\footnotetext{
${ }^{10} \mathrm{O}$ método científico tradicional propiciou a produção de verdades absolutas e fechadas em si mesmas como, por exemplo, a verdade da teoria sociológica da anomia social de Durkheim; a verdade da teoria econômica do livre mercado; a verdade da teoria política da governabilidade; a verdade das teorias psicológicas gestalticas, comportamentais, sistêmicas e psicanalíticas; a verdade das teorias marxistas, a verdade das teorias jurídicas penais e assim por diante.
} 
Terceiro, a realidade humana e social não se esgota em si mesma por aglutinar, de forma dinâmica, complexa e contraditória, o uno e o múltiplo de suas próprias determinações, particularidades e totalidades (SEVERINO, 1995; SPOSATI, 1995; SAWAIA, 1995; RODRIGUES ON, 1995; FRIGOTTO, 1995; ETGS, 1995).

Por isso ela nunca será estática, invariável e absoluta e, portanto, qualquer conhecimento produzido sobre um determinado objeto investigado será, sempre, um processo constante de aproximações sucessivas à realidade estudada, ou seja, um processo de objetivação que objetiva minimizar a interferência da subjetividade do pesquisador.

Portanto, falar em "Verdade" na esfera das profissões que compõem as ciências sociais e humanas implica partir do pressuposto de que todo o conhecimento adquirido acerca da trajetória de vida pessoal, familiar e social dos seus usuários está circunscrito inerentemente a uma realidade que é, essencialmente, histórica e relacional. Dessa forma, derruba-se, também, o mito da ciência tradicional de que é possível, utilizando os métodos adequados, produzir leis universais e invariáveis sobre os objetos de estudo das ciências humanas e sociais.

\section{O Imperativo de se Pensar A Necessidade e o Desafio de Práticas Interdisciplinares no Contexto Judiciário}

A prerrogativa das verdades produzidas pelas ciências humanas e sociais torna eminente uma análise reflexiva que privilegie um "olhar de (e para) dentro" da natureza "psicossocial" do assessoramento prestado aos magistrados da justiça do Distrito Federal e, assim, fazer a crítica na direção da possibilidade de, efetivamente, se pensar em práticas interdisciplinares no âmbito das penas e medidas alternativas.

Sendo assim, iniciaremos a análise pela discussão dos aspectos teóricos, técnicos, éticos e institucionais que norteiam, paradoxalmente, o universo "psi", o universo "social" e o universo "jurídico-legal" que, isoladamente, se propõem esgotar todas as determinações e particularidades do conflito judicializado em nome, muitas vezes, de uma apologia ao consenso, à conciliação e à harmonia social. 
Começaremos pelo universo "jurídico-legal" que contempla, na presente análise, a ciência do Direito (e as leis como seu objeto) e a organização judiciária como sua expressão materializada.

\section{A necessidade e o Desafio do Saber Jurídico-Legal}

O surgimento do estado democrático de direito no Brasil possibilitou ao poder judiciário ampliar as suas funções sociais e institucionais na resolução dos conflitos e dissídios entre os cidadãos, os cidadãos e o Estado e entre o próprio Estado, principalmente no que diz respeito à garantia dos direitos difusos, coletivos e sociais, sob a ótica da garantia da segurança jurídica e da paz social (CASTRO, 1998; FARIA, 1989,1996; ALAPANIAN, 2008).

Entretanto, esta ampliação, em suas intenções, tem esbarrado na prevalência do paradigma normativista que vê o direito como um "indicador privilegiado dos padrões de solidariedade social, [garantindo] a decomposição harmoniosa dos conflitos por via da qual se maximiza a integração social e realiza o bem comum" (SOUSA SANTOS, 2001, p.162). Este mesmo paradigma prioriza o modelo corretivo de justiça, no qual as condições e estruturas sociais baseadas na desigualdade social, econômica, política e cultural são subjugadas aos princípios da legalidade e neutralidade da lei.

Alia-se ao paradigma normativista e ao modelo corretivo de justiça um conjunto complexo de ritos e procedimentos processuais burocratizados e impessoais que, justificados em nome da certeza e da segurança do processo, primam pela formalidade, imparcialidade e hierarquia (FARIA, 1989,1996).

$E$, de forma direta, obstaculizam qualquer possibilidade de reconhecimento e expressão dos indivíduos judicializados como sujeito partícipe da decisão judicial e do processo de responsabilização penal, como veremos adiante.

Do ponto de vista estritamente judicial, o paradigma normativista tem concebido a estrutura de organização e funcionamento do judiciário como simples "administração da lei", tida como instituição neutra, imparcial e objetiva, ficando o magistrado convertido num mero técnico do direito positivo, competente na integração dos sujeitos judicializados, considerados "disfuncionais" na vida social. 
Sua neutralidade e a sua imparcialidade, conjugadas com uma hermenêutica positivista que o obriga a interpretações restritas e objetivas dos códigos, converte-se em condição básica para a legitimação de uma concepção específica de ordem e segurança. Trata-se, pois, de uma interpretação passiva de instituição judicial, expressa pela postura formal distante das diferentes matizes de caráter histórico, ideológico e sociológico que particularizam o trâmite do julgamento, execução e extinção do processo judicial ${ }^{11}$.

Ao mesmo tempo em que tem promovido um processo de modernização das suas estruturas técnico-jurídicas e técnico-organizativas para garantir a sua quota parte na garantia da resolução dos conflitos, o judiciário o faz dentro da lógica da adequação e adaptação da realidade social, dos fatos, valores e interesses contraditórios aos preceitos jurídicos e legais (CASTRO, 1998).

\section{A Necessidade e o Desafio dos Saberes Psíquicos e Sociais: o Paradoxo da Tutela Institucional e do Cuidado Profissional}

Uma forma de ilustrar como o paradigma normativista e o modelo corretivo de justiça se expressam de forma mais explícita é analisar o contexto jurídico-legal das penas e medidas alternativas.

Apesar de não ser intenção oferecer ao leitor uma leitura aprofundada sobre o fenômeno da criminalidade e do penalismo como seu reverso, há um consenso não hegemônico entre os estudiosos da criminologia de que o crime e a pena são fenômenos determinados sócio-histórica e culturalmente. E, portanto, estão presentes em todas as formas de organização social e possuem múltiplas e complexas determinações não esgotáveis ou reduzíveis a explicações meramente metafísicas e empiricistas ${ }^{12}$.

O que interessa trazer para reflexão é tanto o caráter teleológico embutido na aplicação das penas ditas "alternativas"13 como os impactos que um conhecimento

\footnotetext{
${ }^{11}$ Os críticos do direito apontam para a necessidade da magistratura ter uma formação menos dogmática para que possam preencher, na aplicação das normas abstratas aos casos concretos, o hiato existente entre a igualdade jurídico-formal e as desigualdades sócio-econômicas (FARIA,1996), ou melhor, "...a igualdade dos cidadãos perante a lei e a desigualdade da lei perante dos cidadãos" (SOUSA SANTOS, 2001, p.165).

12 Para se aprofundar nas diferentes correntes teóricas que explicam o fenômeno da criminalidade ver THOMPSON (1983), BARATTA (2002), ZAFARONI (1991) e FOUCAULT (1987).

${ }^{13}$ As penas e medidas alternativas estão regulamentadas na lei 9.714/98 que estabelece as condições legais necessárias para que o sujeito em conflito com a lei seja beneficiado com uma pena ou medida
} 
meramente empiricista e/ou reduzidamente positivista sobre o crime e as penas podem obstaculizar qualquer tentativa de se pensar em modelos de análise e intervenção interdisciplinar no contexto judiciário.

Vamos dizer inicialmente que o crime é, de modo geral, um ato de violação, de contrariedade e de negação de normas e regras socialmente determinadas, compartilhadas e garantidas mediante aparatos legais e institucionais.

Entretanto, ao buscar as suas bases explicativas, o direito penal brasileiro o fez a partir da teoria criminológica positivista que compreende o crime como um produto natural da lógica social, com o objetivo de identificar no indivíduo uma personalidade natural voltada para o crime ou, quando muito, atribui ao "meio social" está personalidade, desconsiderando as determinações sócio-históricas e estruturais que envolvem o fenômeno.

Em contrapartida, as penas seriam, também, medidas determinadas, compartilhadas e garantidas mediante aparatos legais e institucionais, visando punir os atos considerados criminosos dentro da lógica da correção. Todavia, no caso das penas e medidas alternativas, vistas como mais "humanas" que a pena de prisão, acopla-se à punição a perspectiva da reparação, da retribuição e da "educação".

De igual modo, a lógica jurídico-legal que norteia a aplicação de uma pena ou medida alternativa, e seu efetivo cumprimento, está na sua capacidade de instigar no sujeito individual a "culpa" necessária para gerar o arrependimento necessário para, daí, gerar a sua responsabilização em relação ao ato cometido e à pena imposta e, assim, promover a integração do "criminoso" e prevenir a reincidência.

Entretanto, há um grande fosso entre a sua finalidade e os seus reais alcances, tanto pelos próprios limites impostos pelas estruturas de funcionamento e organização do judiciário brasileiro apontadas acima, quanto pelas múltiplas e complexas determinações envolvendo o fenômeno do crime e da pena. Estas múltiplas e complexas determinações aparecem, muitas vezes, de forma fragmentada, refratada e

alternativa. As penas alternativas são sanções de natureza criminal como multa, prestação de serviço à comunidade, prestação pecuniária e limitação de fim de semana. Já as medidas alternativas são sanções que não privam a liberdade, mas restringem direitos como a perda de bens e valores e a interdição temporária de determinados direitos como a suspensão da Carteira Nacional de Habilitação (ZAFARONI,1991). 
individualizada pelos saberes que marcam presença no cenário da aplicação e execução da pena ou medida alternativa, inclusive os saberes psicológicos e sociais.

O cenário jurídico-legal de aplicação das penas e medidas alternativas tem como pano de fundo o espectro do policiamento e da fiscalização, condição básica para "garantir" ou "instigar" a responsabilização legal do sujeito individual que, do ponto de vista processual, será materializada com o cumprimento da pena ou medida alternativa imposta.

Como toda a base de determinação e aplicação legal da pena ou medida alternativa está assentada no modelo normativo e corretivo de justiça, a sua eficácia está restrita meramente a completude do ciclo do processamento, julgamento, execução e extinção da medida judicial imposta. Portanto, a medida desse processo de responsabilização é dada, oficialmente, mais pela quantidade de penas ou medidas extintas e menos pelo alto número de reincidência.

Então, considerando o princípio da responsabilização penal do sujeito tutelado judicialmente e - sendo o assistente social partícipe direto da resolução do conflito criminal - como pensar e problematizar teórica, técnica e eticamente o pressuposto da responsabilização penal do ponto de vista profissional, na direção do "cuidado" e da "emancipação"?

Ou seja, é possível pensar em outros balizadores metodológicos que não tornem uno o olhar sobre a efetiva capacidade da pena alternativa provocar uma "internalização" das leis e normas sociais, e que o espaço hegemônico de restrição de direitos se torne, ao mesmo tempo, espaço privilegiado de garantia de direitos?

Talvez a resposta não esteja apenas no complexo conjunto de ritos processuais e nos excessos de formalismos e burocratismos que historicamente caracterizam o judiciário brasileiro, mas na dificuldade dos seus agentes (diga-se magistrados, promotores, defensores, assistentes sociais, psicólogos e pedagogos) sairem das "armadilhas" teórico-metodológicas e técnico-profissionais que cristalizam verdades absolutas e ocultam toda complexidade e totalidade que envolve a realidade humanosocial e institucional.

De igual modo, o paradigma da responsabilização somente adquire uma dimensão "para além" do campo jurídico-legal se houver espaço para questionamento da 
linearidade das verdades teóricas utilizadas pelos magistrados, assistentes sociais, psicólogos e pedagogos.

O primeiro ponto a ser destacado diz respeito à necessidade se fazer uma crítica interna ao corpo de conhecimentos teóricos, das competências técnicas e do compromisso ético que estes agentes dispõem para dar orientação e direcionalidade à análise e intervenção na realidade cotidiana da execução das penas e medidas alternativas.

No que diz respeito ao universo "jurídico-legal", apontado nas linhas anteriores, a preponderância do pensamento positivista e do paradigma normativista e corretivo da justiça criminal denuncia a necessidade da sua desconstrução e, conseqüentemente, a construção de novos pilares teórico-metodológicos na base epistemológica do Direito e, particularmente, no direito penal.

No que se refere ao universo "psíquico" e "social", a justiça do Distrito Federal vêm historicamente incorporando à sua divisão social do trabalho setores denominados regimentalmente de "psicossociais" para assessorar os magistrados das áreas cíveis, criminais e infracionais, o que pressuporia, num primeiro momento, uma tendência teórico-metodológica interdisciplinar.

Entretanto, se indevidamente analisada, a abordagem psicossocial pode levar os profissionais a armadilhas teórico-metodológicas obstaculizadoras a qualquer esforço de mudança de paradigma no processo de responsabilização no espectro das penas e medidas alternativas ${ }^{14}$.

Primeiro, porque há, por assim dizer, uma disposição dos assistentes sociais de incorporarem de forma acrítica o termo "psicossocial" sem a devida responsabilidade de provocar internamente uma análise crítica das bases teóricas e conceituais e as implicações prático-reflexivas da sua utilização na compreensão e explicação das demandas cotidianas que se tornam objeto de análise e intervenção profissional (SOUZA, 2004).

\footnotetext{
${ }^{14} \mathrm{O}$ que se tem denominado de psicossocial, no âmbito da justiça do Distrito Federal, não tem nada a haver com a corrente psicossociológica que, teórica e metodologicamente, objetiva conjugar dialeticamente a teoria psicanalítica e a teoria marxista. Na verdade, perpassa entre os profissionais de Serviço Social e Psicologia a visão funcionalista da abordagem psicossocial. Ver Souza (2004) para analise da visão funcionalista psicossocial; e Castro; Machado \& Araújo (2001) para aprofundamento da teoria psicossociológica.
} 
Como conseqüência, prevalece no âmbito da maioria dos profissionais das psicossociais uma visão simplista e equivocada do que seja interdisciplinaridade. Ou seja, teoricamente a terminologia psicossocial implicaria uma visão interdisciplinar, mas institucionalmente os setores psicossociais são compostos, na verdade, por equipes multiprofissionais $^{15}$ e o processo interventivo acaba sendo disciplinar porque não incorpora outras teorias potencialmente explicativas do real e, quando incorporam, caem num verdadeiro ecletismo ${ }^{16}$ (SOUZA, 2004).

\section{É possível Pensar a Interdisciplinaridade no Âmbito das Penas e Medidas}

\section{Alternativas?}

O primeiro passo para sair da armadilha da banalização e simplificação é reconhecer que o conceito de interdisciplinaridade é inacabado, por ser dinâmico e processual.

O segundo passo é reconhecer que a interdisciplinaridade não é um recurso meramente didático capaz de integrar e reunir as dimensões particulares dos diferentes saberes numa totalidade harmônica, numa verdadeira salada metodológica (FRIGOTTO, 1995) e nem uma ação meramente técnica que incorpora elementos de uma teoria em outra apenas como informação, sem que os pressupostos teóricos e metodológicos das áreas de conhecimento sejam questionados (ETGS, 1995).

Logo, pensar uma análise interdisciplinar no âmbito das penas e medidas alternativas implica, no plano prático-operacional, que se estabeleça mecanismos e estratégias de efetivação do diálogo solidário entre as diferentes áreas. Não basta, por exemplo, ter uma estrutura institucional com justaposição de disciplinas, se não houver um processo de discussão que explicite as correlações e as reciprocidades de significação entre o jurídico, o psíquico e o social.

\footnotetext{
${ }^{15}$ Segundo Vasconcelos (1997) a abordagem multidisciplinar se distingue da interdisciplinaridade por não intentar um exercício constante de reflexão e de práticas profissionais que impliquem reciprocidade, complementaridade, aprendizagem mútua, horizontalização das relações de poder e decodificação recíproca da significação, das diferenças e convergências dos conceitos e princípios fundamentais de cada área.

${ }^{16} \mathrm{O}$ ecletismo é uma das armadilhas mais comuns que se expressam nos setores psicossociais do Tribunal de Justiça do Distrito Federal e Territórios e, particularmente, na Vara de Execução de Penas e Medidas Alternativas, na medida em que permite que diferentes, e até antagônicas, correntes teóricas sejam utilizadas na análise e intervenção das demandas cotidianas. Ver Faleiros (1999)
} 
O terceiro passo é ter claro que nenhum trabalho interdisciplinar se efetiva se não for, primeiro, capaz de transcender a fragmentação do ser e do saber uno e linear, a autonomização dos vários aspectos de manifestação do real, a reificação de teorias explicativas da realidade, a hierarquização entre os saberes e sua relação com o poder, heranças fortes do empiricismo e do positivismo ${ }^{17}$.

A condição de subsidiários das decisões judiciais induz os profissionais de Serviço Social a se identificarem, erroneamente, como o "terceiro olho da justiça", ao mesmo tempo que os colocam numa posição subalterna em relação ao campo jurídico, o que já obstaculiza qualquer tentativa de se pensar a interdisciplinaridade no contexto do judiciário.

Com isso, acabam "tomando para si" prerrogativas que são próprias do discurso jurídico-legal como o controle, a fiscalização, o policiamento e a inquirição, na maioria das vezes sem fazer as devidas mediações que permitam revelar todas as determinações, particularidades e as totalidades envolvidas no seu saber profissional.

Contraditoriamente, se identificam e se reconhecem como equipe psicossocial, mas, na verdade, projetam olhares diferenciados, e muitas vezes excludentes, sobre o fenômeno estudado. E, assim, justificam esta projeção aos limites jurídico-legais e técnico-profissionais, e em nome das "especificidades" de cada área.

Por outro lado, o recurso restrito às especificidades profissionais delineia, sobremaneira, uma dimensão excludente, interna e externamente. Externamente, porque dicotomiza o objeto psíquico e o objeto social, ou seja, diferencia, separa e hierarquiza aquilo que é, dialeticamente, inseparável. Internamente, porque existe no eixo epistemológico de cada área de conhecimento, diferentes (e divergentes) concepções teóricas que problematizam, a partir do seu objeto "específico", a realidade humana e social.

Há nos setores psicossociais tendências teórico-metodológicas sistêmicas, comportamentais e psicanalíticas, típicas do objeto "psíquico"; e tendências funcionalistas, fenomenológicas e marxistas típicas do objeto "social" que produzem e reproduzem apropriações teóricas radicais, rivalidades profissionais em torno da

\footnotetext{
${ }^{17}$ Ver Severino (1996), Frigotto (1995), Etgs (1995), Sposati (1995), Sawaia (1995).
} 
privacidade do seu objeto de estudo e dos acervos metodológicos problematizados privilegiadamente em cada área do conhecimento.

A constatação que se pode fazer é que ao reproduzir o discurso da abordagem psicossocial como sinônimo de interdisciplinaridade, os profissionais dos setores psicossociais fazem-no excluindo das suas supostas "intervenções psicossociais" não só outras teorias presentes no interior de cada profissão, mas aquelas inerentes às outras áreas de conhecimento.

A conclusão que se chega está na direção de que os profissionais que compõem o assessoramento psicossocial, em particular o assistente social, padecem do mesmo engessamento teórico-metodológico e técnico-profissional dos magistrados, com a agravante de criar, entre eles, o paradoxo entre a tutela institucional e a "emancipação" dos sujeitos judicializados.

No contexto das penas e medidas alternativas, este paradoxo se explicita no desafio de atender à prerrogativa legal da "tutela", "fiscalização" e "policiamento" e, ao mesmo tempo, orientar os saberes psíquicos e sociais na direção do "cuidado profissional". Ou seja, caminhar na perspectiva de transformar o espaço de restrição de direitos em espaço de emancipação e resgate da condição de sujeito dos indivíduos judicializados na direção da consolidação, garantia e ampliação de direitos (SOUZA, 2006).

Por outro lado, a utilização do balizador interdisciplinar não significa, necessariamente, a constituição de uma "superciência" que elimine as diferenças e especificidades, mas que as diversas áreas se reencontrem e se complementem, contraditória e dialeticamente.

Agora, na falta deste balizador, o que prevalece é a mera dinâmica da responsabilização penal, pois, sem a devida leitura dos aspectos psíquicos e sociais nela envolvidos, corre-se o risco de apreendê-la apenas superficialmente de forma que o seu alcance se restrinja somente a uma "vigilância" assistida e ininterrupta (no sentido da não reincidência).

Sawaia (1995) nos dá um exemplo ilustrativo do ato de roubar que, segundo ela, não é impulsionado apenas pela falta de algo, mas pelo modo como essa falta é representada, o que vai depender das atividades dos indivíduos e das idéias hegemônicas, 
mas também da forma como esse indivíduo subjetiva essas idéias durante seu processo de socialização.

Por essa via, o estabelecimento das verdades construídas nos estudos "psicossociais" durante o processo de responsabilização penal (diga-se, de vigilância), não perpassa, como afirma Muchail (1995, p.63), pela reconstituição dos fatos, mas pela objetivação do indivíduo e na ordem do que é certo ou errado, permitido ou interditado, correto ou incorreto, em suma, normal ou não.

Mas, o que torna a interdisciplinaridade um possível balizador metodológico que permite uma olhar múltiplo sobre as diversas manifestações e determinações da realidade humana e social, como aparecem no judiciário em forma de conflito? Como é possível se utilizar dela, de forma responsável e crítica, para compreender e explicar, nas mediações e contradições institucionais da execução das penas e medidas alternativas, a relação entre a tutela institucional e emancipação social?

A primeira constatação que precisa ser feita está na premissa de que nenhuma especialidade é capaz de exaurir determinada problemática, de forma que o esforço é sempre aproximativo, acumulativo e processual na busca de um conhecimento (ou de uma verdade) que é sempre relativa, parcial e incompleta.

Por essa via, a interdisciplinaridade torna-se um desafio e uma necessidade fundada, nas palavras de Frigotto $(1995$, p.27) "no caráter dialético da realidade social que é, ao mesmo tempo, una e múltipla e na natureza subjetiva de sua apreensão".

Como conseqüência, é preciso reconhecer que a interdisciplinaridade não se reduz a um mero método de investigação, uma técnica didática, um instrumento utilitário, ou um modelo metodológico capaz de produzir idéias generalizadoras ou universalizantes.

Ao contrário, é preciso pensar a interdisciplinaridade como uma postura profissional que permite por em trânsito o "espaço da diferença" com sentido de busca, de desvelamento da pluralidade de ângulos que um determinado objeto investigado é capaz de proporcionar, que uma determinada realidade é capaz de gerar, que diferentes formas de abordar o real podem trazer (RODRIGUES ON, 1995).

A interdisciplinaridade pode revelar-se, então, como uma alternativa para transpor as fronteiras instituídas pelo saber jurídico-legal e os saberes psíquicos e sociais e, em particular pelos saberes dos assistentes sociais da Vara de Execução das Penas e Medidas 
Alternativas. Da mesma forma, explicita, criticamente, as concepções da realidade, os conhecimentos e os pressupostos e categorias de análise utilizados nos estudos "jurídicos" e "psicossociais", deslocando-os para fora de sua linguagem específica.

É preciso que cada campo abra sua "caixa preta" para o outro, criando uma linguagem comum mediante a qual eles apreendam o construto do outro e o seu próprio, compreendendo o que cada um está fazendo, descobrindo e reconstruindo estratégias de ação, tanto no seu interior de sua própria ciência, como com relação às outras e ao um mundo do cidadão comum (ETGS, 1995).

Não significa, portanto, a perda da sua especificidade e nem apropriação do saber do outro, como tendencialmente aparece nos discursos e nas práticas dos profissionais das "psicossociais" do Tribunal de Justiça do Distrito Federal e Territórios, em especial na Vara de Execução de Penas e Medidas Alternativas. Ao contrário, a interdisciplinaridade requer a originalidade e a diversidade dos conhecimentos produzidos permitindo a pluralidade de contribuições para compreensões mais consistentes do objeto investigado (RODRIGUES ON, 1995).

Como resultado, seria possível romper com as visões simplistas e superficiais que perpassam a compreensão do ser, do saber e do fazer dos profissionais do Direito, da Psicologia e do Serviço Social ${ }^{18}$. Na prática, significa superar o figurativismo normativo e legal no Direito, a visão de homem abstrato que presta conta a si mesmo na Psicologia, e o coletivismo radical que gera a dissolução do indivíduo no Serviço Social (SAWAIA, 1995).

Sendo assim, apontar o caráter dialético da realidade, fundando-o nos princípios da totalidade, contradição e mediação, permite-nos situar a interdisciplinaridade como o caminho do meio para se restabelecer a unidade e a identidade entre os fenômenos subjetivos e sociais, entre o individual e o coletivo, entre o simples e o complexo, o universal e o particular.

Parafraseando SAWAIA (1995, p.101) "é compreender que nada aparece como coletivo sem que antes tenha sido vivido, subjetivamente, enquanto necessidade e

\footnotetext{
${ }^{18}$ A internalização institucional do termo psicossocial provoca a homogeneização da identidade dos profissionais de Serviço Social e Psicologia que compõem os setores psicossociais do Tribunal de Justiça do Distrito Federal e Territórios, reproduzindo visões simplistas e equivocadas sobre as habilidades e competências inerentes a cada área, com a agravante desta homogeneização sobrepor e sobrevalorizar o saber psicológico sobre o saber social numa tendência de "psicologização" do assessoramento. Ver Souza (2004).
} 
sentimento do Eu. E que estas necessidades e sentimentos são sociais e não naturais ou genéticos".

Ao remeter o caráter dialético da realidade como resposta ao prevalecente paradigma legal da responsabilização no âmbito das penas e medidas alternativas, que hierarquiza e sobrepõe o conhecimento e a prática jurídico-legal em detrimento dos conhecimentos e das práticas "psíquicas" e "sociais", abrimos o caminho à prática interdisciplinar.

Esta prática permite, sobremaneira, instaurar uma matriz de justiça e de direito mais coletiva e social, no sentido de ser não uma regularidade de enquadramento, advinda do alto, portanto da homogeneidade, mas uma possibilidade de captar as diferenças e fazer da presença da diferença também um direito de legitimidade ${ }^{19}$ (SPOSATI, 1995).

Só assim será possível, por exemplo, sair do domínio institucional da responsabilização penal que faz com que muitas das práticas dos profissionais das psicossociais da Vara de Execução das Penas e Medidas Alternativas sejam práticas reguladoras do enquadramento, da expulsão da diferença e não da possibilidade de diferença.

$\mathrm{Na}$ verdade, a direção que se precisa seguir está no horizonte interno da leitura crítica da realidade, em sua totalidade e complexidade, que inclui, dialeticamente:

- Resgatar a complexidade e totalidade da vida social;

- Analisar as particularidades da instituição judiciária nesta totalidade, bem como as diferentes formas e conteúdos assumidos pelo fenômeno da criminalidade e da penalidade na conjuntura mundial, nacional e local;

- Identificar as especificidades das diferentes áreas de conhecimento que problematizam os conflitos criminais judicializados no âmbito das penas e medidas alternativas;

- Problematizar as peculiaridades teórico-metodológicas, técnicas e ético-políticas que orientam a escuta e a postura profissional, identificando e distinguindo as demandas

\footnotetext{
${ }^{19}$ Segundo Sposati (1995), o exercício do Direito no Brasil tem sido muito mais o palco do exercício da condescendência do que efetivamente de justiça, de forma que o Direito termina sendo uma regulação pela homogeneidade, escapando a possibilidade no âmbito da diferença, embora se esteja numa sociedade desigual.
} 
que são institucionais, profissionais e do próprio usuário e, principalmente, a responsabilidade profissional de tornar o espaço de restrição de direitos em espaço de garantia de direitos;

- Apreender as condições objetivas e subjetivas de vida dos usuários, bem como as formas simbólicas de representação e significação desta realidade pelos outros profissionais, pelos magistrados e pelos próprios usuários.

Em suma, acreditamos que para se construir um modelo de justiça que conjugue interdisciplinarmente o campo jurídico-legal às outras esferas da vida social é preciso reconhecer que os saberes sejam jurídico, psicológico e social devem buscar a unicidade da essência humana e social dos sujeitos judicializados.

\section{Referências}

ALAPANIAN, S. Serviço Social e Poder Judiciário: reflexões sobre o Direito e o Poder Judiciário. Ed. Veras, volume I, São Paulo: 2008.

Serviço Social e Poder Judiciário: reflexões sobre o Direito e o Poder Judiciário. Ed. Veras, volume II, São Paulo: 2008.

BARATTA, A. Criminologia crítica e crítica do direito penal: introdução à sociologia do Direito Penal. Tradução de Juarez Cirino dos Santos. Coleção Pensamento Criminológico. Ed. Revan, Rio de Janeiro: 2002.

CARNOY, M. Estado e Teoria Política. Ed. Papirus, Campinas, São Paulo: 2000.

CASTRO, F.A.V de. O poder judiciário na virada do século:paradigmas de atuação. Ed. Lúmen Júris, Rio de Janeiro: 1998.

CERVO, A.L;BERVIAN, P.A. Metodologia Científica. Ed. Plano, São Paulo: 1983.

ETGS, N.J. Ciência, interdisciplinaridade e Educação. In: Interdisciplinaridade: para além da filosofia do sujeito. (Org.) Jantsch, A P e Bianchetti, L. Ed. Vozes, Petrópolis: 1995.

FALEIROS, V.P.Estratégias em Serviço Social. Ed. Cortez, São Paulo: 1999.

FARIA, J.E. Direito e Justiça: a função social do judiciário. Ed. Ática, São Paulo: 1989. . O Poder Judiciário no Brasil: paradoxos, desafios e alternativas. Conselho de Justiça Federal, Centro de Estudos Jurídicos, série monografias, volume 03, Brasília: 1996. FOUCAULT, M. Vigiar e Punir:história da violência nas prisões. Tradução de Raquel Ramalhete. Ed. Vozes, Petrópolis, Rio de Janeiro: 1987. 
FRIGOTTO,G. A interdisciplinaridade como necessidade e como problema nas ciências sociais. In: Interdisciplinaridade: para além da filosofia do sujeito. (Org.) Jantsch, A P e Bianchetti, L. Ed. Vozes, Petrópolis, Rio de Janeiro: 1995.

GOLDENBERG, M. A arte de pesquisar. Ed. Record, Rio de Janeiro, São Paulo: 1997.

HAGUETTE, T.M. F. Metodologias qualitativas na sociologia. Ed. Vozes, Rio de Janeiro: 2000.

MINAYO, M. C. de S. O Desafio do conhecimento: pesquisa qualitativa em saúde. Ed. Afiliada, HUCITEC, São Paulo/Rio de Janeiro: 1994.

MUCHAIL, S. T. De práticas sociais à produção de saberes. In: O Uno e o Múltiplo nas relações entre as áreas do saber. (Org.) Martinelli, M.L; Rodrigues On, M.L e MUCHAIL, S.T. Ed. Cortez, São Paulo: 1995.

RIBEIRO, J. O que é positivismo. Coleção Primeiros Passos, Ed. Brasiliense, São Paulo: 2001.

RODRIGUES ON. M.L. O Serviço Social e a perspectiva Interdisciplinar. In: O Uno e o Múltiplo nas relações entre as áreas do saber. (Org.) Martinelli, M.L; Rodrigues On, M.L e MUCHAIL, S.T. Ed. Cortez, São Paulo: 1995.

SOUSA SANTOS, B. Introdução à ciência pós-moderna. Ed. Graal: Rio de Janeiro: 2001.

SAWAIA, B.B. A Falsa cisão retalhadora do homem. In: O Uno e o Múltiplo nas relações entre as áreas do saber. (Org.) Martinelli, M.L; Rodrigues On, M.L e MUCHAIL, S.T. Ed. Cortez, São Paulo: 1995.

SEVERINO, A.J. O poder da verdade e a verdade do saber. In: O Uno e o Múltiplo nas relações entre as áreas do saber. (Org.) Martinelli, M.L; Rodrigues On, M.L e MUCHAIL, S.T. Ed. Cortez, São Paulo: 1995.

SPOSATI, A. O conhecimento da verdade e o exercício do poder. In: O Uno e o Múltiplo nas relações entre as áreas do saber. (Org.) Martinelli, M.L; Rodrigues On, M.L e MUCHAIL, S.T. Ed. Cortez, São Paulo: 1995.

SOUZA,M.F. As condições, determinações e particularidades do processo de trabalho do assistente social nos órgãos do poder judiciário sediados em Brasília. Dissertação de mestrado em Política Social. Departamento de Serviço Social e Pós-graduação em Política Social, da Universidade de Brasília: 2004;

A participação do assistente social na judicialização dos conflitos sociais.

Revista Ser Social, n. 19, Departamento de Serviço Social, Universidade de Brasília, julho a dezembro: 2006.

THOMPSON, A.Quem são os criminosos? Ed. Achiamé, Rio de Janeiro: 1983.

TRIVIÑOS, A. N. S. Introdução à pesquisa em ciências sociais. Ed. Atlas, São Paulo: 1992. 
VASCONCELOS, E.M. Serviço Social e Interdisciplinaridade: o exemplo da saúde mental. Serviço Social e Sociedade, n. 54, Ed. Cortez, São Paulo: 1997.

ZAFARONI, E. R. Em busca das penas perdidas: a perda de legitimidade do sistema penal. Tradução Vânia Romana Pedrosa e Amir Lopes da Conceição. Ed. Revan, Rio de Janeiro: 1991. 